\title{
A gênese e o processo de desenvolvimento social e econômico da aglomeração urbana da fronteira de Uruguaiana/BR e Paso de los Libres/AR
}

\author{
La génesis y el proceso de desarrollo social y económico de la \\ aglomeración urbana de la frontera de Uruguaiana/BR y Paso de \\ los Libres/AR
}

\section{The genesis and the process of social and economic development of urban agglomeration border of Uruguaiana/BR and Paso de los Libres/AR}

\author{
Cláudia Heloiza Conte \\ claudiaheloiza@yahoo.com.br \\ Universidade Estadual de Londrina, UEL, Londrina, PR
}

Resumo: Este trabalho pretende compreender como se deu a gênese das cidades de Uruguaiana/RS (Brasil) e Paso de los Libres (Argentina), além de analisar a dinâmica social e econômica das mesmas na atualidade. Para tanto, são abordados os processos de colonização e formação das cidades, especialmente durante o século XIX, o início das atividades econômicas, como pecuária, comércio e rizicultura, e seus desdobramentos no decorrer do tempo. Busca-se, através da categoria de formação socioespacial, entender a dinâmica desta aglomeração urbana de fronteira. Verificou-se que, o setor terciário possui importância fundamental do ponto de vista dos empregos gerados, embora o maior destaque neste conjunto são os serviços de transporte ligados a Estação Aduaneira. Mesmo sendo o câmbio elemento primordial para a determinação do fluxo comercial entre a população dessas cidades, o comércio e os serviços comandam a dinâmica no sentido de empregos gerados e, juntamente com a pecuária, constituise em atividade econômica que mantem a formação socioespacial desta aglomeração urbana de fronteira.

Palavras-chave: Dinâmica, formação socioespacial, atividades econômicas.

Resumen: Este trabajo intenté comprender cómo se dio la génesis de las ciudades de Uruguaiana/RS (Brasil) y Paso de los Libres (Argentina) así como analizar la dinámica social y económica de las mismas en la actualidad. Para ello, se abordan los procesos de colonización y formación de las ciudades, especialmente a longo del siglo XIX, el inicio de las actividades económicas, cómo ganadería, comercio y de ricicultura, y sus desdoblamientos a lo largo del tiempo. Se busca, a través de la categoría de formación socio espacial, entender la dinámica de esta aglomeración urbana de frontera. Se descubrió que el sector terciario es de fundamental importancia desde el punto de vista de los empleos creados, aunque lo más destacado en este conjunto son los servicios de transporte vinculados a la Estación Aduanera. Sin bien el tipo de cambio es un elemento clave para determinar el flujo comercial entre la población de estas ciudades, el comercio y los servicios impulsan la dinámica hacia los empleos creados y, junto 
con el ganado, constituyen una actividad económica que mantiene la formación socio espacial de esta aglomeración urbana fronteriza.

Palabras clave: Dinámica, formación socio espacial, actividades económicas.

Abstract: This paper aims to understand the genesis of Uruguaiana/RS (Brazil) and Paso de los Libres (Argentina), as well as to analyze the social and economic dynamics of the cities currently. It was focused on the processes of colonization and formation of the cities, mainly along the XIX century, the beginning of economic activities as livestock, commerce, and rice cultivation, and their unfolding over time. Through the socio-spatial formation category, it is sought to understand the dynamics of this urban agglomeration of the frontier. It was found that the tertiary sector has great importance about jobs creation, although its main highlight is the transport services linked to the customs station. Even the exchange rate is a key element in determining trading flows between the two cities, trading and services drive the dynamics towards jobs creating. Adding livestock, they maintain the socio-spatial formation of this border cities agglomeration.

Keywords: Dynamics, socio-spatial formation, economic activities.

\section{INTRODUÇÃO}

Este trabalho tem como elemento principal a discussão sobre a dinâmica da aglomeração urbana das cidades fronteiriças de Uruguaiana/RS, no Brasil, e Paso de los Libres, na Argentina. De acordo com o Ministério da Integração Nacional (BRASIL, 2005), trata-se de uma das aglomerações urbanas de fronteira que possui maior dinâmica econômica no contexto sul-americano. Este artigo é uma versão ampliada e detalhada do artigo Gênese e dinâmica das aglomerações urbanas de fronteira: Uruguaiana e Paso de los Libres, Corumbá, Puerto Suárez e Puerto Quijarro, Foz do Iguaçu, Ciudad del Este e Puerto Iguazú, publicada na Revista Geosul, v.32, n.65, de set./ dez. 2017. Aqui a discussão aprofunda-se na análise da aglomeração urbana de Uruguaiana/BR e Paso de los Libres/AR.

As conceituações associadas às aglomerações urbanas começaram a ser discutidas com mais profundidade quando grandes centros urbanos passaram por fortes transformações; a partir do crescimento populacional e aumento da produção industrial, bem como do desenvolvimento de sistemas de transportes, que possibilitaram a dispersão da cidade, gerando, em muitos casos, aglomerações de centros urbanos de distintos municípios. Beaujeu-Garnier e Chabot (1970, p.21) explicitam que, aglomeração urbana é "[...] una noción más extensa que la de ciudad y más precisa que la de área suburbana", visto tratar-se de uma junção entre duas ou mais cidades, seja pela intensificação de vínculos ou pela expansão territorial urbana.

Parcela importante dos estudos sobre aglomerações urbanas abordam regiões metropolitanas de grandes cidades, mas é importante frisar que esse processo também ocorre em pequenas e médias cidades, em escala nacional e internacional. Nas aglomerações de fronteira, trata-se de um processo intensificado mediante expansão e complexidade da urbanização, no entanto fluxos e deslocamentos ocorrem desde a gênese das mesmas. 
Além disso deve-se considerar que a aglomeração urbana não precisa necessariamente de continuidade do tecido urbano, pois é a intensidade das relações a conceitua como tal.

O termo fronteira deriva do latim, fazendo referência a uma porção do território situado à frente (FERRARI, 2014). Na França, a palavra fronteira (frontéire) surgiu no início do século XIV e a sua utilização ocorreu através dos militares que iam ao front para defender o território real contra possíveis invasores. Para isso eram construídas fortificações militares, que posteriormente passaram a ser chamadas de fronteira. Assim, a expressão abarca duplo sentido, o movimento de conquista e fixação de demarcação e delimitação das zonas conquistadas. A formação dos Estados nacionais no contexto da Europa colaborou para que o termo fronteira fosse reconhecido enquanto limites políticos dos Estados nacionais. Machado (1998, p. 41) argumenta que:

A origem histórica da palavra mostra que seu uso não estava associado a nenhum conceito legal e que não era um conceito essencialmente político ou intelectual. Nasceu como um fenômeno da vida social espontânea, indicando a margem do mundo habitado. Na medida em que os padrões de civilização foram se desenvolvendo acima do nível de subsistência, as fronteiras entre ecúmenos tornaram-se lugares de comunicação e, por conseguinte, adquiriram um caráter político.

Ao serem criados, os estados nacionais já receberam um espaço dividido, visto que preexistia aos territórios uma separação espacial do trabalho e uma divisão política do território. "Com o desenvolvimento do capitalismo a divisão do mundo em territórios nacionais se sedimenta, e é com base nesta estrutura que as sociedades politicamente se enquadram" (CATAIA, 2007, p.3).

A perspectiva desse estudo é realizar uma análise dos processos de constituição e evolução das cidades desta aglomeração urbana na fronteira sul do Brasil, do conjunto de atividades econômicas desenvolvidas, das relações entre essas atividades e da dinâmica das mesmas e suas devidas relações com as suas formações socioespaciais. É a formação socioespacial, entendida como uma totalidade, que permite a análise do que é singular a cada país e que, vista como um método, pode evitar comparações descontextualizadas entre os diferentes Estados-nação.

Santos (1977, p.81) deixa claro que as formações socioespaciais, enquanto etapas de um processo histórico, referem-se a “[...] evolução diferencial das sociedades” , isto é, expressam a diferenciação espacial e, por conseguinte, são dados fundamentais para explicar por que países, regiões e centros urbanos diferenciam-se uns dos outros. Esses participam do processo geral implementado pelo modo de produção dominante, com graus diferentes de copresença e de complexidade, pois se definem tanto pela "[...] sua existência corpórea [na esfera da materialidade] quanto por sua existência relacional".

Esta análise será apresentada em duas partes, onde será abordada a gênese das cidades de Uruguaiana e Paso de los Libres e posterior análise da dinâmica social e econômica das mesmas na atualidade. 


\section{GÊNESE DE URUGUAIANA E PASO DE LOS LIBRES E A ATIVIDADE PASTORIL}

A ocupação inicial da porção sul do estado do Rio Grande do Sul, onde se encontra a cidade de Uruguaiana, foi realizada pelos padres da Companhia de Jesus. A disputa entre Portugal e Espanha pelas terras da América do Sul ocorreu por longo período em torno do Tratado de Tordesilhas, que definia os limites de fronteira, mesmo sem constar precisamente onde se encontravam esses limites. Aqui é necessário considerar que, ao entrar em contato com o universo subdesenvolvido ou pré desenvolvido, como nos mostra Rangel (1981), a Europa não mediu esforços para inserir a América nos moldes feudais, sendo o Tratado de Tordesilhas um marco deste esforço. Ao mesmo tempo que dividia-se o continente americano entre as Coroas de Espanha e Portugal "[...] estatuía que todas as nossas terras pertenciam ao rei - um ou outro, pouco importava do nosso ponto de vista" (RANGEL, 1981, p.6).

Não existindo o reconhecimento do direito indígena ao território, considerável parte das terras eram tratadas enquanto áreas vazias. Assim, os limites seguiriam os acidentes físicos, em especial as fronteiras fluviais. Schaffer (1991) aponta que as fronteiras terrestres dos países sul-americanos foram marcadas pela dispersão do povoamento, pelos vazios humanos, pela falta de clareza nos traçados, pelos conflitos, pela posse de terra e pela fragilidade dos vínculos entre países vizinhos.

Considerando que nos primeiros anos de ocupação da área de Uruguaiana a população local era pequena e a demanda por alimentos reduzida, a quantidade de gado era grande. Esse período ficou marcado como a época do couro, expressão usada de forma pragmática, pois neste momento o couro era a parte mais valorizada e aproveitável do boi, sendo que na maioria das vezes a carne era ignorada, já que a mesma não poderia ser conservada, devendo ser consumida logo após o abate do animal.

É a partir da doação de sesmarias ${ }^{1}$ na região de Uruguaiana que verifica-se o processo de formação de estâncias para a criação de gado, a formação de povoados e da economia baseada na atividade pastoril. Isso ocorreu a partir de 1814 com o objetivo de ocupação do espaço físico. Assim, através das referidas doações, ocorreu a oficialização da grande propriedade rural, que marca a constituição da base fundiária da fronteira oeste gaúcha. Neste sentido Fonseca (1983) explicita que a grande propriedade não é apenas característica da fronteira, de certo modo é um elemento da própria economia pecuarista.

Para a compreensão da formação socioespacial de uma área é fundamental considerar os elementos físicos. A Figura 1 apresenta o relevo desta área de fronteira, predominantemente composto por campos e bosques esparsos de araucárias, o que favoreceu a criação de gado e posteriormente o cultivo de arroz. Luvissolos, que se estendem para áreas vizinhas na Argentina e Uruguai, caracterizam-se pela pouca profundidade e pelo acúmulo de argila.

1 De acordo com Ferreira (1994), as sesmarias eram lotes de terras cedidos pela Coroa Portuguesa a pessoas que quisessem cultivá-las, chamadas sesmeiros, que eram obrigados a pagar uma sexta parte dos frutos da terra. Era justamente o dízimo da Ordem de Cristo, representada pela Coroa Portuguesa. 
Figura 1 - Aspectos de vegetação e relevo do Rio Grande do Sul e localização de Uruguaiana (estado do Rio Grande do Sul, Brasil) e Paso de los Libres (província de Corrientes, Argentina).

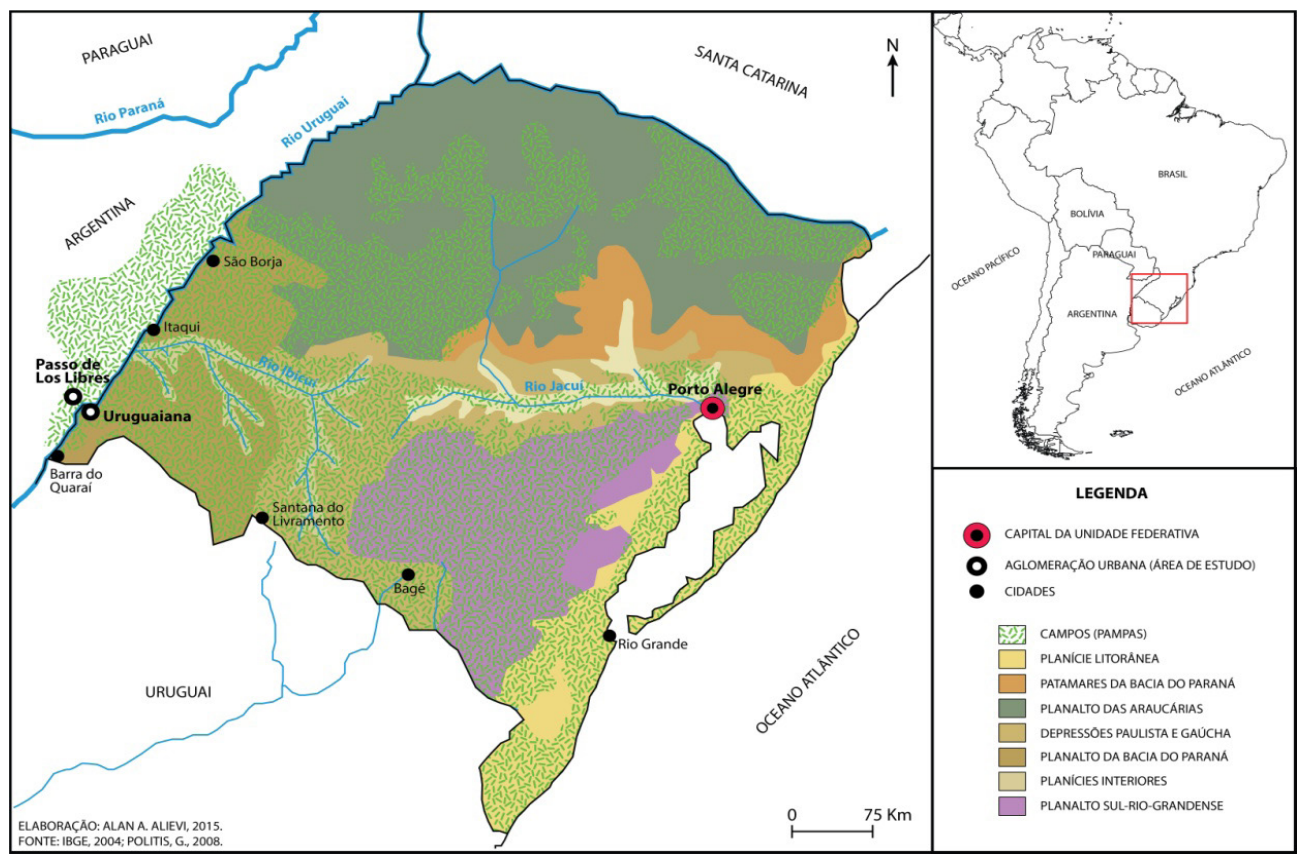

Org.: a autora.

Em relação a gênese de Paso de los Libres deve-se frisar que antes da fundação da província de Corrientes, a área estava ocupada pela estância missioneira de Yapeyú, que compreendia os municípios de Itaqui, São Borja, Uruguaiana e algumas cidades fronteiriças da Argentina e do Uruguai, entre elas o atual território de Paso de los Libres. Neste contexto Grimson (2003, p. 51) explicita que:

Yapeyú, la más meridional de las reducciones jesuiticas, fundada en 1626 y donde luego nacería el general San Martin, se encuentra a solo $60 \mathrm{Km}$ al norte de Pasos de los Libres. Desde Yapeyú se fundaron diversas estancias y en 1742, hacia el final de la presencia jesuitica, se habría inaugurado un oratorio en el lugar donde más tarde se fundaría Pasos de los Libres. Como el río Uruguay no era frontera para los jesuitas, sino una de las principales vías de transporte entre las poblaciones, también la zona de la actual Uruguayana habría sido incorporada a la estancia de Yapeyú. Es probable que la región de Libres y Uruguayana se constituyera en la última zona periférica que las misiones alcanzaron, aunque sin consolidar su dominio.

A efetiva ocupação da província de Corrientes teve início juntamente com a colonização espanhola. O primeiro povoamento foi Vera San Juan, hoje a capital da província, também com o nome Corrientes e fundada em 1588. Do século XVIII até as primeiras décadas do século XIX as fundações de vilas na província de Corrientes foram ocorrendo paulatinamente, sendo que uma dessas foi Paso de los Libres, criada em 1843. De acordo com Schaller (2001), o processo de povoamento foi difícil, em grande parte por conta da resistência dos indígenas que ali viviam. Soma-se a isso a carência de incentivos políticos e econômicos repercutindo negativamente no desenvolvimento do local. Em relação as 
atividades desenvolvidas, o autor aponta que, neste período, as mesmas baseavam-se na agricultura de subsistência local.

A pecuária, assim como ocorrido em Uruguaiana, teve início através do aproveitamento do gado deixado pelos jesuítas. No século XVIII iniciou-se a criação de gado nas estâncias, sendo que a partir desse momento a atividade teve crescimento com a demanda de mercados regionais, especialmente Misiones e Paraguai. Desde o final do século XVIII, com a abertura do porto de Buenos Aires para o comércio internacional em 1760, houve acréscimo nas exportações e crescente demanda por couro e produtos derivados que estimularam o estabelecimento de estâncias na região (GRIMSON, 2003).

De forma similar ao realizado no Brasil, o governo imperial espanhol implantou uma política de concessão de terras com objetivo de colonização e organização territorial. Schaller (2001) explicita que uma das consequências do avanço territorial foi a paulatina transferência de terras do governo para o domínio particular. A política de concessão de terras teve início a partir da fundação da cidade de Corrientes e o critério inicial era a doação das mesmas para aqueles que nelas residiam há certo tempo.

A ocupação das áreas onde Uruguaiana e Paso de los Libres, embora distintas em relação aos países colonizadores, ocorreu no mesmo período e manteve características similares no que diz respeito às atividades desenvolvidas. A ocupação a partir dos jesuítas promoveu relações econômicas e sociais constantes entre os povoados ali existentes. Embora neste período as discussões sobre limites e fronteiras já houvesse iniciado, o movimento nesta fronteira era constante e o rio não impedia a circulação de pessoas, visto que os estancieiros e os trabalhadores (escravos ou peões) por ali circulavam e relacionavam-se.

A partir de 1822 a cessão de direitos sobre as terras através das sesmarias no Brasil foi extinta, entretanto era possível a posse de terras devolutas por aqueles que tinham intuito de cultivá-las. A ocupação realizada a partir desse momento era conhecida como 'posse com cultura efetiva' (HERRLEIN, 2004). O autor afirma que as alterações nas formas de ocupação das terras não foram suficientes para impulsionar o surgimento de pequenos e médios produtores rurais em Uruguaiana. Somente em 1850, através da Lei das Terras, como ficou conhecida a lei $n^{0} 610$, é que as terras devolutas passaram a ter caráter legal. Lima (1990), no entanto, afirma que esta lei buscava estabelecer uma nova medida para controlar a apropriação das terras do Estado uma vez que a maneira como as terras foram adquiridas antes da lei conduziram a alguns problemas, sobretudo a falsificação de documentos com o propósito de sua legitimação, tanto para sesmeiros quanto para posseiros.

Foi na segunda metade da década de 1820 que surgiu o primeiro aglomerado da povoação ribeirinha, o que mais tarde se tornaria Uruguaiana. A povoação formou-se nos arredores do Passo de Santana, local onde já existia uma guarda portuguesa e que em décadas anteriores encontrava-se o Porto de Santana Velha, utilizado para realizar a travessia dos jesuítas e indígenas (PONT, 1983). Contudo, após sofrer as consequências de uma grande enchente, atrelado a possibilidade de organização do povoamento que vinha crescendo, iniciou-se entre os políticos mais influentes da República Farroupilha ${ }^{2}$,

2 Para aprofundamento do assunto ler Dorneles (2010). 
a discussão sobre o local ideal para a definitiva ocupação da nova povoação. Em 1843 foi criada a Capela de Sant'Ana do Uruguai; três anos depois, com o fim da Revolução Farroupilha, foi assinada a lei que elevava a Capela do Uruguai a condição de vila, recebendo o nome de Uruguaiana, separada de Alegrete. Isabelle $(1949$, p.51) aponta que:

É uma vila de pelo menos 2.000 habitantes, onde se manifesta, em todos os recantos, a mais viva atividade comercial. Só franceses existem mais de cem no lugar, entre eles gente de muito boa educação e irrepreensível conduta. Em Uruguaiana quase não se reconhece uma cidade brasileira, mas uma hispano-francesa, que parece apoiar-se em suas relações de vida e de comércio, mais em Buenos Aires e Montevidéu, do que em Porto Alegre e Rio Grande.

Gradualmente, motivado pelo crescimento da vila, o comércio de Uruguaiana com Buenos Aires e Montevidéu foi constituindo-se e fortalecendo-se. Isso se deu porque o porto de Uruguaiana era um dos melhores do Rio Uruguai para a efetivação do comércio de mercadorias importadas dos dois países vizinhos, descartando a necessidade de realizar transações pelo mar. Naquele período a navegação fluvial mostrava-se mais segura, além dos produtos chegarem mais rapidamente ao interior do continente.

De acordo com Flôres (1996), a vila explorava o comércio internacional legal nos primeiros anos de sua criação, quando exportava mercadorias com valores bastante significativos no total das exportações da província. As exportações eram compostas por produtos derivados da indústria pastoril, especialmente couro e charque e destinavam-se para o Uruguai, Argentina, Alemanha, França, Chile, Cuba, Bélgica, Inglaterra, além de estados brasileiros como Rio de Janeiro e Pernambuco.

A partir de 1850 Uruguaiana tornou-se zona comercial, possuindo livre navegação, situação que facilitava o contrabando e reduzia os custos das mercadorias para demais cidades do interior. As décadas de 1850 e 1860 representaram o auge dos abates e exportações do charque, contudo esse momento foi marcado também pela alta do preço dos escravos e a crescente concentração dos mesmos nas mãos de poucos charqueadores, pela perda do mercado consumidor do Sudeste para as charqueadas platinas e queda dos preços do charque. De acordo com Soares (2006), a partir da década de 1860 Argentina e Uruguai voltam sua produção para os frigoríficos estrangeiros e as charqueadas estavam praticamente ausentes de suas unidades produtivas, cabendo as charqueadas gaúchas suprir o mercado de charque que estes países abasteciam.

Os últimos marcos de delimitação da fronteira entre Brasil e Argentina foram fixados em $1862^{3}$. O primeiro tratado feito entre o Império Brasileiro e a Confederação Argentina ocorreu em 1856, com considerações sobre as fronteiras dos dois países, que continham referências sobre a comercialização e a livre navegação nos rios Uruguai e Paraguai.

Pesavento (1980) aponta que, no final do século XIX, no estado do Rio Grande do Sul existiam mais de trinta charqueadas, sendo que Uruguaiana contava com uma unidade, a

3 Deve-se considerar que a Argentina na época não havia ainda se consolidado como República e era um Estado Confederado, ou seja, a união de Estados nacionais que mantêm sua autonomia - a Confederação Argentina era formada pelas províncias de Entre Rios, Corrientes e Santa Fé (COLVERO, 2003). 
charqueada Barra do Quaraí. As charqueadas fundadas no estado concentravam-se, em sua maioria, nos municípios da fronteira, sendo Bagé considerado o polo charqueador gaúcho.

Nesta discussão deve-se considerar que, a dinâmica e o funcionamento das estâncias estavam relacionadas com a presença do agregado, do peão e do escravo. A composição de classes é importante para a compreensão do processo de formação socioespacial dessa área de fronteira, bem como a continuidade e as mudanças que foram ocorrendo nas atividades produtivas, neste caso em específico, da pecuária. Quando Queiroz (1977) aponta a existência de agregados nas estâncias, trata-se de um tipo de relação de trabalho onde o trabalhador, ao prestar serviços ao estancieiro, recebia uma parcela da terra para manter suas próprias atividades de subsistência, compostas de lavoura e criação de pequenos rebanhos. Nas palavras de Zarth (2002, p.172), o agregado mantinha uma relação de dependência com o proprietário, "[...] que lhe concedia o direito de morar em troca de produtos e da prestação de serviços, pelo qual poderia ser remunerado".

Os peões, por sua vez, eram remunerados tanto através de dinheiro quanto através de produtos, só que diferente dos agregados, não possuíam vínculos com os proprietários, sendo na maioria das vezes trabalhadores temporários. Os peões eram contratados por dia ou tarefa e permaneciam nas estâncias por alguns dias ou semanas, principalmente nos períodos de maior atividade - marcações, castrações, busca de animais evadidos e formação de tropas para as charqueadas (FARINATTI, 2008), enquanto os escravos compunham a parcela daqueles trabalhadores permanentes, responsáveis por todas as tarefas relacionadas a criação de gado ${ }^{4}$.

Uruguaiana foi elevada à condição de sede municipal em 1874 e no ano seguinte foi criada a comarca de Uruguaiana, separando-a de São Borja (PONT, 1983). O comércio da cidade foi favorecido através da instalação da estrada de ferro, que juntamente com a navegação através do rio Uruguai, aproximou a mesma de outros centros urbanos da região do Prata. A ferrovia ligava Barra do Quaraí a Itaqui e foi construída pela empresa inglesa Brazil Great Southern Railway. Esta ferrovia foi ampliada em 1907, ligando Uruguaiana a Porto Alegre.

A cidade, portanto, teve crescimento atrelado aos processos de importação e exportação de produtos, tendo sua importância aumentada de acordo com a demanda por produtos, bem como pelo acréscimo da população urbana, que passou a ocupar-se de atividades comerciais. As charqueadas representaram um período dinâmico para a pecuária, e juntamente com o comércio tornaram Uruguaiana uma cidade importante no contexto nacional e internacional.

Paso de los Libres foi criada a partir de transformações que ocorreram na Argentina. Em 1829 Juan Domingos Rosas assumiu o poder na Argentina, em um momento de enfrentamento entre unitários e federalistas, tanto em Buenos Aires como nas províncias.

La administración de Rosas fue eminentemente conservadora y centralista. Representó a la propiedad, especialmente a la gran propiedad rural, y fue tradicionalista en su política social. Rosas gobernó para una clase: la de los estancieros y saladeristas. No

4 A população do Rio Grande do Sul em 1872 era de 434.813 habitantes, sendo 15\% (67.022) de escravos. 
se planteó aumentar los gravámenes a los comerciantes y productores. Es decir, la administración protegió decididamente a la gran economía (OPERÉ, 2011, p.15).

Diante de uma série de manifestações por parte dos federalistas, que não aceitavam o autoritarismo com que Rosas conduzia seu governo, o partido organizou uma liga diplomática que buscava a participação das províncias do interior e do litoral nas rendas do porto de Buenos Aires, a livre navegação nos rios e a autonomia provincial absoluta.

Una concatenación de movimientos conspirativos y revueltas ostigatorias había empujado al régimen a una posición límite. Se produjo el bloqueo de la escuadra francesa al puerto de Buenos Aires (1838-40), así como la invasión de la margen izquierda del Uruguay por el caudillo oriental Rivera. Este había firmado un tratado de mutua defensa con las tropas correntinas por el cual el Gobernador de la provincia, Berón de Astrada, declaraba la guerra a Rosas en desacuerdo con la preponderancia que Buenos Aires ejercía sobre la libre navegación de los ríos (OPERÉ, 2011, p.20).

Nos anos finais da luta contra Rosas, o general Madariaga juntamente com seus aliados, que encontravam-se exilados no Brasil, retornaram para a Argentina e iniciaram “[...] la invasión de Corrientes cruzando el Uruguay por la barra del arroyo Itapitocay, situado algo al sur de Uruguayana, y en 1 de abril de 1843 se reunieron en la banda argentina, precisamente en el Rincón de San Jorge" (OTAZÚ, 2003, p.22). Foi neste momento que ocorreu a marcha para a cidade de Corrientes e a tomada do governo provincial.

Com a caída de Rosas e a reorganização nacional, iniciou-se uma nova etapa política e institucional na província de Corrientes, através da reativação do comércio e o desenvolvimento da pecuária. Outro processo importante foi a privatização das terras em Corrientes, e em Paso de los Libres, a partir da segunda metade do século XIX. Foi neste contexto, após Madariaga retornar do Brasil e derrotar o governo de Corrientes, que o mesmo tornou-se governador da província e fundou o povoado de Paso de los Libres.

La fundación de Paso de los Libres y Uruguayana es un resultado del conjunto de los procesos económicos y políticos regionales hacia mediados del siglo XIX: el dinamismo comercial de rio Uruguay, las luchas de los gobiernos locales contra los poderes centrales, sus alianzas mutuas, su expansión hacia la costa del Uruguay (GRIMSON, 2003, p.64).

Nos primeiros anos do povoado a província de Corrientes encontrava-se afastada economicamente de Buenos Aires, fato que favoreceu o desenvolvimento do mesmo, já que todo o comércio exterior da província de Corrientes ocorria ali. Em 1862 o povoado foi elevado à condição de vila e nesse mesmo ano foi instalado o governo municipal; contudo a cidade alcançou sua autonomia apenas em 1934 (COELHO, 2008).

Até meados do século XIX a existência de gado na região do rio Uruguai era bastante limitada, constituindo uma pequena parte da produção da província de Corrientes (PESAVENTO, 1980). Como consequência do avanço territorial que incorporou terras baldias da província, entre as décadas de 1850 e 1880, ocorreu um rápido crescimento do estoque de gado nos departamentos da região Oriental, entre eles, Paso de los Libres. Esse 
crescimento e desenvolvimento da pecuária correntina estava ligado ao crescimento da indústria de charqueadas no Rio Grande do Sul e Uruguai, sendo que a venda de gado em pé tornou-se um dos mais importantes itens do comércio da província.

Em relação à atividade terciária, foi a partir de 1850 que o comércio de Paso de los Libres passou a ter representatividade, influenciado principalmente pelos bloqueios comerciais ocorridos no rio Paraná, pela consolidação de centros de intercâmbio com Uruguaiana e com o fim da guerra civil no Rio Grande do Sul. Schaller (2001, p.21) aponta que:

El comercio de Paso de los Libres se efectuaba principalmente con el Brasil. El principal rubro de exportación era el ganado en pie hacia los saladeros riograndenses. Constituía también el punto de depósito de productos brasileños, en particular yerba mate, que luego se introducían en la provincia o se remitía hacia el sur.

Para Schaller (2001), a segunda metade do século XIX foi um período favorável para o progresso das atividades produtivas, contudo esses avanços não poderiam ser comparados ao desenvolvimento que ocorria nas províncias do litoral, onde existiam inúmeras ligações com os mercados europeus. Neste sentido o autor aponta que Corrientes passou definitivamente para condição de "zona marginal", cujos movimentos produzidos pela atividade agropecuária foram um reflexo tardio e limitado das transformações ocorridas na região pampeana.

Através da expansão da indústria do charque no sul do Brasil e no Uruguai, ocorreu a abertura de mercado para os produtores correntinos. Assim, o crescimento das charqueadas promoveu a venda de gado na província e em pouco tempo esta se tornou a principal exportação de Corrientes, constituindo-se na segunda província criadora de gado no contexto argentino (GRIMSON, 2003). A mão de obra utilizada nestes trabalhos não era mão de obra negra, mas indígena.

O crescimento de Paso de los Libres ocorreu intensamente e em 1885 já contava com 10.640 habitantes. Além disso a expansão da criação de gado demandou produtos e serviços, os quais intensificaram a dinâmica da mesma.

Em 1864 teve início a construção das linhas férreas no país. Passados 30 anos, as vias da empresa Nordeste Argentina conectaram Paso de los Libres e Monte Casero, cidade localizada a sudeste de Corrientes. Em 1894 ocorreu a implantação de uma linha férrea ligando Paso de los Libres a Buenos Aires e por conseguinte, ao restante do país, possibilitando o desenvolvimento comercial e agropecuário do município.

Em 1889 foi concluído o trecho da ferrovia Noroeste Del Uruguay, que ligava Uruguaiana até Barra do Quaraí. Desta última foi criada pela Brazil Great Southern - BGS, a linha até Itaqui, ligando-as ao restante do estado do Rio Grande do Sul. A Figura 2 apresenta esta ligação ferroviária, a ligação rodoviária existente entre Uruguaiana e demais cidades brasileiras, bem como sua ligação com Paso de los Libres. 
Figura 2 - Ferrovias e rodovias na aglomeração urbana de Uruguaiana/Paso de los Libres.

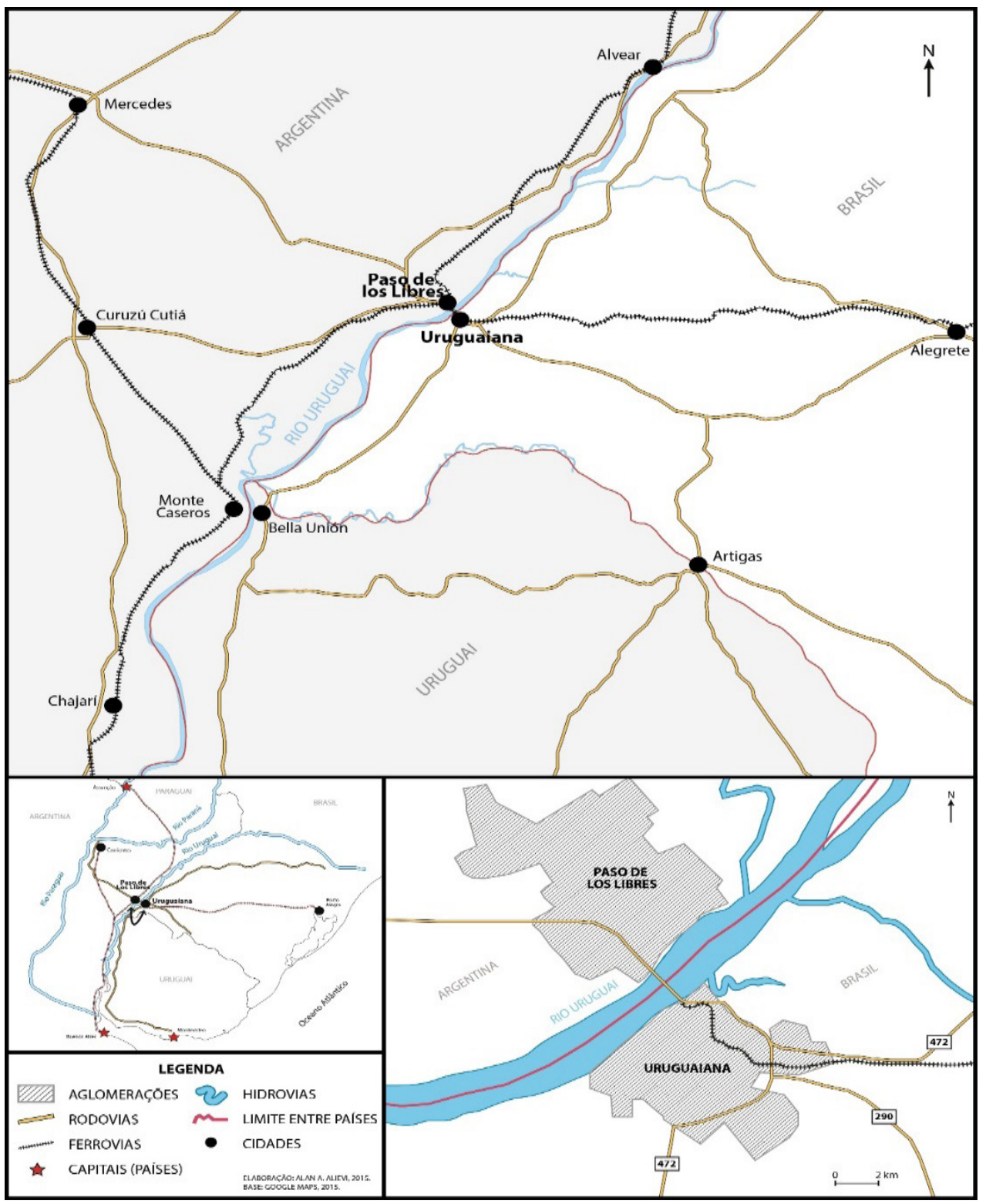

Org.: a autora.

No final do século XIX o preço pago pelo gado diminuiu consideravelmente, o que motivou o processo de decadência econômica da porção sul do estado do Rio Grande do Sul. Isso se deu basicamente por dois motivos: pela concorrência do charque produzido nos países platinos, além da redução do consumo de charque. Mesmo assim, durante esse período cerca de $60 \%$ das exportações eram representadas pelos produtos da pecuária. Em relação ao setor secundário, Uruguaiana apresenta uma industrialização incipiente. Em 1930, de acordo com Maestri (1989), existiam 30 indústrias e 562 trabalhadores. Neste período as charqueadas já haviam perdido importância, embora continuassem sendo o segundo setor mais representativo, com duas unidades e 270 trabalhadores. A indústria de vestuário constituía-se no maior setor industrial de Uruguaiana, com oito unidades e 320 trabalhadores. A abertura das indústrias de vestuário está relacionada com a Primeira 
Guerra Mundial e a demanda por lã e seus derivados pelos países envolvidos no conflito. Neste mesmo período Uruguaiana apresentou acréscimo na criação de ovelhas.

Em Paso de los Libres, até 1910 a economia do município girava principalmente em torno do porto e do comércio que mantinha com Uruguaiana, bem como a pecuária. $\mathrm{Na}$ contrapartida, a indústria não apresentou destaque, visto que estas eram representadas por pequenas unidades e direcionadas ao abastecimento local. Segundo Otazú (2003), em 1912 Paso de los Libres era caracterizada como uma cidade de "fuertes casas de comercio", contudo o elemento que mais movimentava o comércio era o contrabando.

Foi no final da década de 1920 que se iniciou o cultivo de arroz em Paso de los Libres. "[...] son precisamente las campañas libreñas las primeras en acoger este nuevo cultivo gracias a sus campos nivelados e inundables y a su proximidad e mayores contactos con Brasil - el gran productor por entonces" (OTAZÚ, 2003, p.25). Dados referentes aos produtores, à produção e comercialização do arroz em Paso de los Libres, especialmente neste período, são escassos na bibliografia disponível.

O início do século XX indicou uma diferenciação entre as economias de Uruguaiana e Paso de los Libres. Embora tenha ficado evidente uma crise na pecuária de Uruguaiana, verificou-se crescimento nas suas atividades urbanas, fato não ocorrido na mesma proporção na cidade argentina. Estas diferenças no processo de crescimento e expansão das atividades econômicas de Uruguaiana e Paso de los Libres não diminuíram as relações entre as mesmas, principalmente do ponto de vista do comércio entre brasileiros e argentinos.

\section{DINÂMICA SOCIAL E ECONÔMICA DE URUGUAIANA E PASO DE LOS LIBRES NA ATUALIDADE}

A expansão do agronegócio brasileiro nos últimos cinquenta anos provocou grandes alterações na estrutura de mercado e na introdução da agropecuária no complexo produtivo. A análise produtivista desse processo leva ao erro de considerá-lo apenas sob a ótica da relação mais próxima entre agricultura e indústria, com a crescente intersecção produtiva implantada pelo processo de industrialização advinda da Segunda Revolução Industrial. "Em economias continentais como a brasileira, exigente em irradiar esse processo por largo espaço territorial, essa transformação conforma-se como um autêntico processo de agroindustrialização" (GONÇALVEZ, 2005, p.7).

Neste conjunto observa-se a ampliação dos serviços para agropecuária, de preparação e logística, que representam a incorporação de beneficiamento, transporte, acesso e armazenagem do produto agrícola. Além disso, ocorre o crescimento e o desenvolvimento dos serviços associados às cadeias de produção da agricultura, a exemplo da assistência técnica e manutenção especializada de equipamentos rurais, agroindustriais, laboratoriais e de informática.

Uruguaiana participa ativamente do agronegócio, e neste sentido, a Tabela 1 mostra forte concentração da propriedade da terra, pois em 1980 os pequenos estabelecimentos (com até 100 hectares) representavam $43,5 \%$ do total numérico e apenas 3\% das terras 
ocupadas. Na contrapartida, os grandes estabelecimentos, com mais de 500 hectares, perfizeram $24 \%$ do número total e $79,58 \%$ do total de terras. Em 1996 e 2006 a situação era relativamente similar, pois os pequenos estabelecimentos alcançaram $48 \%$ do total numérico e 4,1\% da área total. Os grandes estabelecimentos representaram 18\% do total numérico e 77,7\% da área total. No Censo Agrícola de 1996 ocorreu aumento das terras ocupadas pelos estabelecimentos com até 100 hectares, isso se deu pela inserção de alguns assentamentos rurais.

Tabela 1 - Estrutura dimensional dos estabelecimentos rurais de Uruguaiana:1980/2006 ${ }^{5}$

\begin{tabular}{c|c|c|c|c|c|c|c|c}
\hline $\begin{array}{c}\text { Grupos de área } \\
\text { (ha) }\end{array}$ & \multicolumn{2}{|c|}{1980} & $\begin{array}{c}\text { Grupos de área } \\
\text { (ha) }\end{array}$ & \multicolumn{2}{c|}{1996} & $\begin{array}{c}\text { Grupos de área } \\
\text { (ha) }\end{array}$ & \multicolumn{2}{c}{2006} \\
\hline Até 49 & $\begin{array}{c}\text { Estab } \\
434\end{array}$ & $\begin{array}{c}\text { Área } \\
7.654\end{array}$ & Até 99 & $\begin{array}{c}\text { Estab } \\
438\end{array}$ & $\begin{array}{c}\text { Área } \\
9.226\end{array}$ & Até 49 & $\begin{array}{c}\text { Estab } \\
540\end{array}$ & $\begin{array}{c}\text { Área } \\
12.794\end{array}$ \\
\hline 50 a 100 & 160 & 11.674 & & & & 50 a 100 & 261 & 16.248 \\
\hline 101 a 500 & 439 & 111.587 & 100 a 500 & 416 & 18.014 & 101 a 500 & 575 & 127.323 \\
\hline + de 501 & 332 & 510.319 & + de 501 & 365 & 599.877 & + de 501 & 301 & 545.600 \\
\hline Total & 1.365 & 641.234 & Total & 1.219 & 627.117 & Total & 1.667 & 701.974 \\
\hline
\end{tabular}

Fonte: IBGE, Censo Agrícola (1980, 1996, 2006), Sistema Nacional de Cadastro Rural (1997).

Sobre as áreas com predomínio de grandes propriedades rurais na Campanha, Chelotti (2011, p.38) evidencia que o processo de modernização não foi capaz de mudar a estrutura fundiária, aliás, concentrou-a ainda mais. "A grande transformação introduzida pelo processo de modernização nessas áreas foi o desenvolvimento da lavoura capitalista do arroz irrigado, que começou a ser desenvolvida em parceria com a pecuária extensiva". A Tabela 2 apresenta os dados referentes a estrutura dimensional dos estabelecimentos rurais de Paso de los Libres em 1988 e $2002^{6}$.

Tabela 2 - Evolução da estrutura dimensional dos estabelecimentos rurais de Paso de los Libres de 1988 a 2002.

\begin{tabular}{c|c|c|c|c}
\hline Grupo de área (ha) & \multicolumn{2}{|c|}{1988} & \multicolumn{2}{c}{2002} \\
\hline Até 49 & Estab & Área & Estab & Área \\
50 a 100 & 203 & 3.366 & 194 & 3.546 \\
101 a 500 & 22 & 2.113 & 38 & 2.865 \\
Acima de 501 & 65 & 17.561 & 78 & 21.307 \\
& 101 & 388.264 & 118 & 410.323 \\
\hline Total & 391 & 409.191 & 428 & 438.041 \\
\hline
\end{tabular}

Fonte: INDEC, Censos agropecuários $(1988,2002)$.

Os estabelecimentos com até 100 hectares predominam sobre o total nas duas datas - em termos de área representaram 1,33\% e 1,46\% em 1988 e 2002. Os grandes

5 Em 2006 algumas mudanças ocorreram na estrutura dimensional dos estabelecimentos rurais de Uruguaiana, pois em 1997 o distrito de Barra do Quaraí foi desmembrado de Uruguaiana. Em 2017, segundo resultados preliminares do IBGE, o número de estabelecimentos agropecuários em Uruguaiana decresceu 33\%, para 1.116, porém a diminuição de área total foi de apenas 2,8\% (530.149,386 ha), confirmando a tendência de concentração da propriedade.

6 Na Argentina os censos agropecuários foram realizados nos anos de 1988, 2002 e 2008, sendo este último realizado de forma incompleta em algumas províncias, como Corrientes e Misiones, justificando a opção por não utilizar tais dados (CNA, 2008). 
estabelecimentos representavam, em números, 25,83\% e 27,57\% dos estabelecimentos em 1988 e 2002 respectivamente, enquanto a área ocupada em 1988 era de 94,86\% e 93,60\% em 2002, ou seja, ocorre forte concentração de terras em Paso de los Libres.

Em relação ao uso da terra em Uruguaiana entre 1980 e 2006, deve-se apontar que a pastagem, elemento fundamental para o desenvolvimento da pecuária, perdeu 14,35\% de área entre 1980 e 2006, mesmo assim, correspondeu a 79,47\% da área total em 2006 (395.085 hectares). Esta diminuição da área de pastagem está relacionada com as técnicas utilizadas na pecuária, especialmente a partir da década de 1990, bem como o desmembramento de Barra do Quaraí do território de Uruguaiana. A área de lavoura temporária manteve-se estável, com relativo aumento em 1996 e correspondendo a 15,89\% da área total em 2006 (497.150 hectares); a lavoura permanente pouco representa nas atividades agropecuárias do município 7 .

Em Paso de los Libres a área de pastagem corresponde a 86,25\% da área total, de 426.386 hectares, fato que evidencia a importância da pecuária para o município, enquanto a área destinada a lavoura temporária perdeu 414 hectares entre 1988 e 2002, totalizando 7.812 hectares em 2002. A lavoura permanente, assim como em Uruguaiana, tem pouca representatividade (215 hectares em 2002).

O arroz destaca-se entre os produtos cultivados em Uruguaiana, com crescimento de 58,9\% entre 1980 e 2006, quando registrou 590.329 toneladas colhidas de 71.124 hectares. A área utilizada, por sua vez, aumentou 15.352 hectares nesse mesmo período ${ }^{8}$. Já a safra de 2015/ 2016 rendeu 695.044 toneladas de uma área de 83.030 hectares (IRGA, 2016). Segundo o Irga (2016), na safra de 2015/2016, dos 258 estabelecimentos que cultivaram arroz, 150 possuíam área superior a 200 hectares. As demais culturas pouco representaram no conjunto da produção agrícola de Uruguaiana, já que a soja, que contou com uma produção de 7.650 toneladas em 1980, passou para uma produção de 480 toneladas em 2006.

$\mathrm{O}$ acesso a políticas de crédito e financiamento foi um dos elementos principais da expansão da agricultura em áreas tradicionais da pecuária. Atrelado a isso tem-se o fato de que Uruguaiana apresenta uma boa potencialidade de produção, devido ao tipo de solo, de média fertilidade natural e com ótima resposta a utilização de fertilizantes químicos, possuindo também baixa capacidade de infiltração de água, elemento fundamental para a garantia de seu uso e manejo, contando com grande número de mananciais, arroios e rios.

Mesmo não contando com indústrias, em Uruguaiana estão instalados os escritórios das principais marcas de arroz. De acordo com o presidente da Associação dos Arrozeiros (2016, com. pess.), todo o arroz produzido em Uruguaiana sai do município em casca e é beneficiado em outros locais, sendo que 24\% do PIB de Uruguaiana em 2016 veio do arroz.

Um elemento fundamental no processo de produção do arroz diz respeito as relações sociais, que em Uruguaiana ocorrem por assalariamento e por contratação temporária. De acordo com o IRGA (2009), para cada 30 hectares cultivados um posto de trabalho é criado 9 . O presidente da Associação dos Arrozeiros ainda salienta que a maior parte dos

7 O Censo Agropecuário de 2017 revela que a área ocupada por pastagens recuou para 70,7\% da área total, com 374.584,01 ha, e de lavouras temporárias subiu para 18\% do total, com 97.538,14 ha.

8 Segundo o IRGA (2016), a área cultivada pode ser alterada (aumentar ou diminuir) de acordo com a disponibilidade de água nas represas.

9 Em 2006, de acordo com o Censo Agropecuário, eram 3.757 empregados permanentes e 489 temporários. Nos resultados preliminares de 2017, já eram 4.829 os empregados permanentes. 
estabelecimentos, embora contrate pessoal para trabalho temporário no período das safras, mantem alguns trabalhadores e suas famílias no próprio estabelecimento, e além do salário, oferecem moradia e participação na produção.

A produção agrícola de Paso de los Libres engloba basicamente o arroz, seguida pela produção de milho (INDEC, 2002). Em relação ao arroz, em 1988 foram colhidas 20.878 toneladas de 9.334 hectares, apresentando queda em 2002, quando foram colhidas 19.965 toneladas de 7.810 hectares. As empresas arrozeiras fecharam quase todas, pois com a ida de produtores brasileiros, especialmente para Mercedes ${ }^{10}$, os processos de produção e comercialização do arroz foram direcionados para outras cidades, onde a produção e beneficiamento do arroz intensificavam-se. Assim, os produtores paulatinamente foram deixando o arroz para dedicar-se especialmente a criação de gado.

Em relação ao rebanho bovino de Uruguaiana, mesmo sendo o mais importante, tanto em cabeças quanto em estabelecimentos, houve queda de $11,33 \%$ no número de cabeças e de $48 \%$ no número de estabelecimentos entre 1980 e 2006 . No entanto é importante destacar que muitos estabelecimentos dedicam-se concomitantemente a criação de gado e a produção de arroz.

O gado criado na cidade gaúcha é destinado ao corte, no entanto o abate e o processamento da carne não são realizados no município, visto que o mesmo conta com apenas um frigorífico, que atende à demanda local. No que diz respeito as relações sociais nesta atividade deve-se apontar que, estas permanecem com as mesmas características, ou seja, pouca mão de obra, majoritariamente assalariada. Neste sentido e de acordo com o presidente da Associação dos Arrozeiros de Uruguaiana (2016), existe o entendimento, tanto dos criadores de gado quanto dos produtores de arroz, que a rizicultura tornou-se uma atividade mais atrativa e rentável em comparação a pecuária.

O rebanho de maior representatividade em Paso de los Libres é o bovino, que em 2002 era o quinto colocado em número de cabeça de gado da província, contribuindo com $6,55 \%$ do total de animais de Corrientes ${ }^{11}$. Em Corrientes destaca-se a criação de gado de cria, onde $68,7 \%$ são construídos por animais da raça Zebu, seguido de $23,7 \%$ de raças europeias, 5,1\% índicas e 2,5\% crioulas. Mesmo assim MacArrein et al. (2006) evidenciam que a província ocupa uma posição periférica na economia pecuarista da Argentina devido aos baixos índices produtivos, ligados principalmente “[...] en planteos de explotación extensivos pastoriles de baja eficiencia. En general la eficiencia productiva de la cría vacuna, rasgo determinante de la producción pecuaria provincial, se encuentra dominada por bajos rendimientos, no superando el $48 \%$ la tasa de marcación de la mayoría de los rodeos" (MacARREIN et al., 2006, p. 15). Paso de los Libres conta com apenas um frigorífico, que é responsável pela carne consumida no município.

A rizicultura tornou-se, ao longo dos anos, a principal atividade agropecuária de Uruguaiana, com intensos investimentos tecnológicos, e mesmo não havendo indústrias beneficiadoras no município, a atividade foi modernizada no decorrer do tempo. Em Paso

10 Muitos arrozeiros de Uruguaiana e demais cidades da Campanha direcionaram-se para cidades da Argentina, Paraguai e Uruguai para produzir arroz, especialmente a partir da década de 1990 e com objetivo de expandir a produção.

11 "Conforme a estimaciones de la Encuesta Nacional Agropecuaria 2001, con datos recogidos al 30 de junio de ese año, Corrientes tiene un total de 3.720 .100 bovinos, lo que representa el 7.6\% del stock bovino del país, mientras que las existencias totales de ganado Bovino en ese ámbito alcanzaron a 48.851 .000 cabezas" (MacARREIN, 2006, p. 16). 
de los Libres a situação foi inversa, ou seja, mesmo com alguma tecnologia empregada, não houve incremento e a cultura perdeu importância ao longo tempo. Apesar de verificar pouca dinâmica entre Uruguaiana e Paso de los Libres no que diz respeito as atividades agropecuárias, as duas cidades participam efetivamente dos agronegócios de seus respectivos países. Nessa aglomeração, caracterizada pela grande propriedade, Uruguaiana insere-se no agronegócio do arroz, com destaque e crescimento anual na produção, enquanto o agronegócio da carne mantem-se estável; Paso de los Libres, inversamente, destaca-se mais no agronegócio da carne do que do arroz, embora constitua-se em importante produtora do último.

Em relação a indústria, Uruguaiana e Paso de los Libres não possuem muita representatividade. Em Uruguaiana o destaque é a construção civil, com crescimento de $91,14 \%$ em quase 30 anos. Assim como na maior parte das cidades do Brasil, Uruguaiana vivenciou o crescimento do setor, que passou de 14 estabelecimentos em 1985 para 158 em 2014, enquanto os empregos saltaram de 285 em 1985 para 739 em 2014 (RAIS, MTE, 2014). Uruguaiana conta com pequenas indústrias, as quais pouco representam no âmbito local e/ou regional. Tratam-se de unidades direcionadas ao abastecimento local e que demandam pouca mão de obra. Em Paso de los Libres não há registro de indústrias de grande porte e que sejam importantes do ponto de vista do número de trabalhadores.

O setor terciário, por sua vez, é fundamental no processo de integração e nos relacionamentos existentes entre a população das aglomerações urbanas de fronteira. As relações comerciais entre Uruguaiana e Paso de los Libres existem praticamente desde a fundação de ambas e foram intensificando-se de acordo com os momentos vividos pelas mesmas. No entanto, foi apenas em 2010, com o Mercosul já estabelecido, que nota-se crescimento nos segmentos do comércio de Uruguaiana.

O comércio varejista apresentou crescimento de $26,3 \%$ no número de estabelecimentos e de 22\% no número de trabalhadores entre 1985 e 2010 (RAIS, MTE, 2014). Da mesma forma, o comércio atacadista apresentou crescimento, com 79 estabelecimentos e 369 trabalhadores. Em Paso de los Libres, no ano de 2014, existiam 221 estabelecimentos de comércio e 1.304 trabalhadores.

Os fluxos comerciais entre Paso de los Libres e Uruguaiana estão intimamente relacionados com o câmbio. Adiala (2006) explicita que, enquanto lugares de contato entre sistemas jurídicos distintos, Paso de los Libres e Uruguaiana são bastante suscetíveis em sua dinâmica em relação as diferenças de normas, em ambos os lados da fronteira política. Além disso, estas cidades sofrem, direta ou indiretamente, os efeitos de crises e crescimentos que ocorrem nos países que pertencem, bem como naqueles que lhe são contíguos. Assim, mudanças cambiais podem, por exemplo, mudar a direção e o volume dos fluxos de mercadorias e deste modo, influenciar o mercado de trabalho, especialmente no setor de serviços que atende ao mercado local. As alterações na dinâmica econômica em nível nacional, por sua vez, podem mudar a direção dos fluxos de mercadorias entre países.

Dos setores de serviço, o que mais cresceu foi o de transporte e comunicação, com 365 estabelecimentos e 2.507 trabalhadores em 2014 (RAIS/MTE, 2014). O crescimento dos serviços de transporte está intimamente relacionado com o Mercosul e com a construção 
da Estação Aduaneira ${ }^{12}$ e todos os processos que ali ocorrem. Para se ter dimensão desta realidade, verifica-se que , o valor de importação foi, entre 2011 e 2015, bem maior do que o de exportação. Em 2011 foram importados US\$ 39.766.233, aumentando para US\$ 49.276.530 em 2013 e caindo novamente para US\$20.924.677 em 2015. Em relação a exportação nota-se que, em 2011 foi exportado o valor de US\$ 5.213.809, diminuindo para US\$ 1.464.038 em 2013 e fechando o ano de 2015 com US\$ 6.667.383 exportados.

Os principais países para os quais o Brasil exportou através de Uruguaiana em 2015 foram o Chile e o Peru, seguido da Argentina, enquanto que, a Argentina, o Uruguai e a China constituíram-se nos países que o Brasil mais importou no mesmo ano. Os produtos mais exportados foram maquinaria agrícola e produtos de origem animal, e os mais importados em 2015 foram arroz, farinhas e veículos, sendo que, dos produtos importados da Argentina, 50\% constituem-se por veículos (ELOG, 2016 $6^{13}$ ).

Os serviços médicos, odontológicos e veterinários e os de educação, não apresentaram crescimento notável no período, mas é fundamental considerar a interpretação de Machado (2005) evidenciando que a assimetria na oferta de serviços é responsável por fluxos transfronteiriços na maioria das cidades, com predomínio de fluxos direcionados ao Brasil. Maior parte deles está ligado aos serviços de saúde, e secundariamente, aos serviços de educação.

Em Paso de los Libres os serviços mais importantes são os setores de transporte, armazenamento e comunicação e as atividades imobiliárias, empresariais e de aluguel. Os hotéis e restaurantes, embora não configurem os mais representativos em números, são importantes no sentido da atratividade de brasileiros.

Es interesante constatar que en Paso de los Libres se encuentran almacenes "para brasileños": vinos, cuero y las prendas de vestir vinculadas al polo o al rugby son objetos elegidos por brasileños de alto poder adquisitivo. Al hablar con propietarios de estas tiendas, ellos aseguraron que $60 \%$ de sus clientes son del país vecino (RASCOVAN, 2010, p.10).

Em relação aos serviços de educação superior, em Uruguaiana existem seis instituições: a Universidade Federal do Pampa - UNIPAMPA, pública, inaugurada em 2006, e cinco instituições privadas, sendo três destinadas ao ensino a distância. Paso de los Libres conta com duas instituições, uma privada e uma pública. A Universidad Nacional del Nordeste - UNNE, oferta o curso de licenciatura em Comércio Exterior, que de acordo com a instituição conta com estudantes de Uruguaiana. O inverso é pouco comum, pois aqueles que tem oportunidade costumam se dirigir a Corrientes ou Posadas para ingressar em um curso universitário. Outra situação a destacar é a ida de brasileiros para cursar medicina na Fundación H. A Barcelo, no município de San Tomé, distante $200 \mathrm{Km}$ de Paso de los Libres. As cidades de aglomerações de fronteira apresentam vantagens posicionais que estimulam medidas específicas como instrumentos jurídicos, que legitimam determinadas

12 Administrado pela empresa ELOG, realiza operações de movimentação, armazenagem e despacho aduaneiro. O porto seco ocupa uma área de 167 mil metros quadrados. De acordo com a gerencia da ELOG, em 2016 a empresa mantinha 160 funcionários, e em todo o Porto Seco trabalhavam cerca de 400 pessoas.

13 Disponível em: http://blog.eloglogistica.com.br/ 
atividades nesses lugares, diferentemente do resto do território, a exemplo da implantação de Zonas de Livre Comércio e Estações Aduaneiras. Por outro lado, esses mesmos lugares se caracterizam por uma instabilidade econômica, resultante das ações políticas e econômicas oriundas de diversas escalas. Isso ocorre, de acordo com Machado (2005), pelo fato de que os espaços fronteiriços são animados por dois tipos de fluxos econômicos. Uns de ordem estrutural, praticamente permanentes, consistindo na troca de bens, serviços e informações entre cidades com características distintas, e outros de ordem conjuntural, que explicam-se pelas flutuações monetárias e por variações dos mercados de produtos agrícolas.

Para Adiala (2006), as interações estruturais entre as duas cidades são explicadas pela presença de intercâmbios contínuos, caracterizados por fluxos transfronteiriços intensos, ligados a questões de trabalho, terra e recursos naturais, capitais e serviços. A autora acrescenta ainda que a construção da ponte internacional é a característica fundamental entre as cidades, sendo um resultado de decisões políticas e intensas negociações, não podendo ser classificada enquanto uma infraestrutura espontânea. A Figura 3 mostra os fluxos econômicos existentes na aglomeração urbana de Uruguaiana e Paso de los Libres, evidenciando as trocas comerciais e de serviços, com destaque para o transporte de mercadorias e para os agronegócios do arroz e da carne bovina.

Figura 3 -Fluxos Econômicos na Aglomeração Urbana de Uruguaiana e Paso de los Libres em 2018.

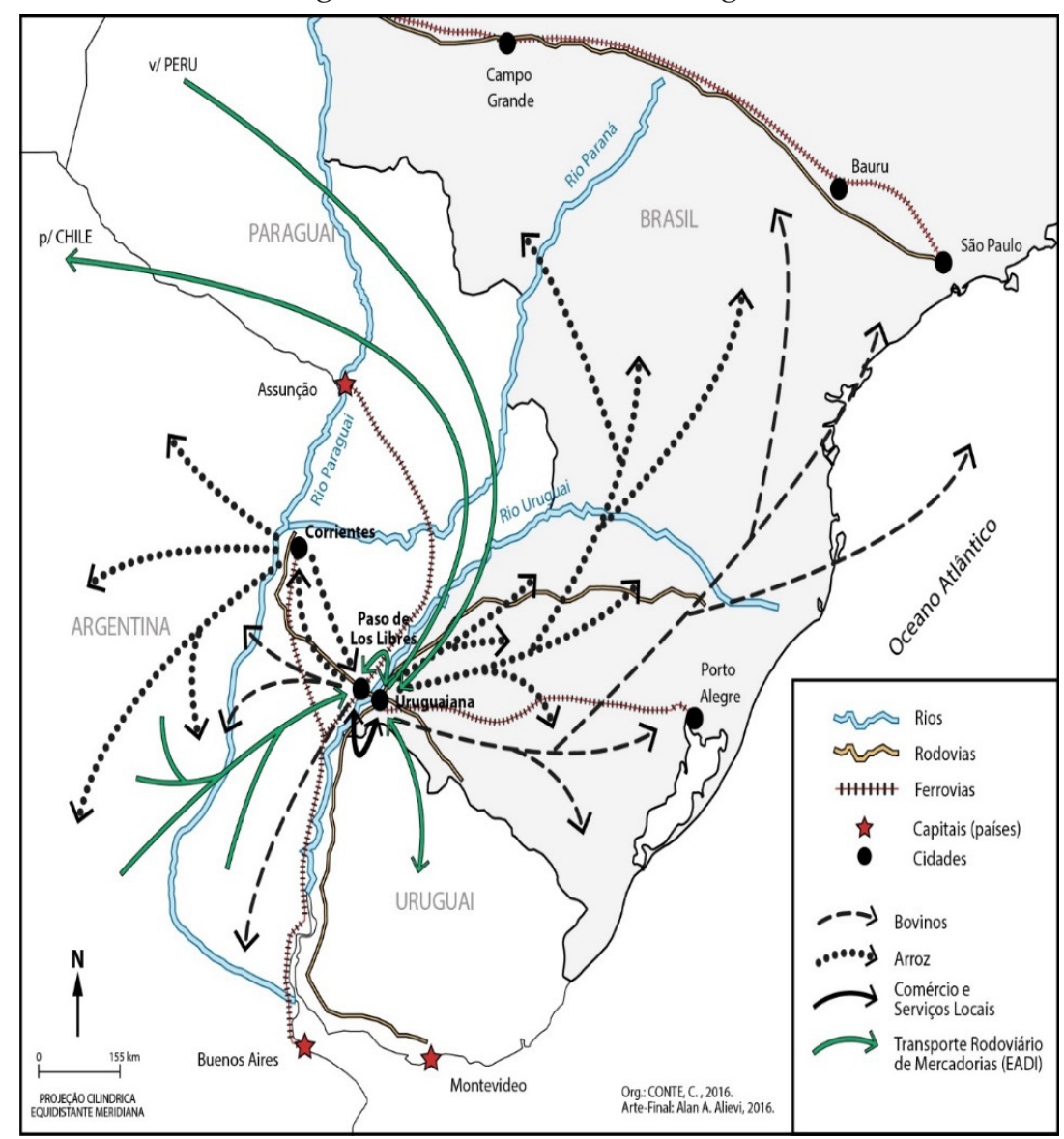

Org.: a autora. 
Essas cidades tem como característica a expressividade do setor terciário, constituindo-se importante empregador formal da população das cidades, e correspondendo, em ambas, a cerca de 60\% do mercado de trabalho formal (ADIALA, 2006). As interações entre as duas cidades estão fundamentalmente relacionadas com as vantagens econômicas proporcionadas nos momentos de variação cambial. Além deste fator, que gera fluxos que variam de direção e intensidade em função da diferença da valorização das moedas, o setor comercial varejista ainda se sustenta minimamente por apresentar as especializações locais, que geram alguma complementaridade (DIETZ, 2008).

\section{CONSIDERAÇÕES FINAIS}

Uruguaiana e Paso de los Libres foram fundadas praticamente no mesmo período e as relações econômicas entre elas estiveram presentes desde a gênese das cidades. $\mathrm{O}$ rio pouco impedia a circulação entre brasileiros e argentinos (GRIMSON, 2003) e o comércio fronteiriço, principalmente de produtos alimentícios, ocorria diariamente. Verifica-se que o processo de integração já ocorria neste momento, o que muda com o passar do tempo são as maneiras em que as relações ocorrem.

Ambas cidades, no decorrer do século XIX, estavam inseridas em formações sociais similares em relação às condições naturais, criação de gado, extensão da propriedade privada e relações servis. As especificidades encontram-se no fato de que em Paso de los Libres não havia o processamento da carne em charque como em Uruguaiana, com o gado criado no município argentino sendo comercializado com Uruguaiana e cidades do Uruguai para serem processados.

O setor terciário, na aglomeração urbana de Uruguaiana e Paso de los Libres, possui importância fundamental do ponto de vista dos empregos gerados, mas o destaque maior neste conjunto são os serviços de transporte ligados a Estação Aduaneira, que reúne o maior número de estabelecimentos e trabalhadores. Mesmo sendo o câmbio elemento primordial para a determinação do fluxo comercial entre as populações dessas cidades, o comércio e os serviços comandam a dinâmica no sentido de empregos gerados e, juntamente com a pecuária, constitui-se em atividade econômica que mantem a formação socioespacial desta aglomeração urbana de fronteira.

\section{REFERÊNCIAS}

ADIALA, C.S.M. de. Efeitos de políticas públicas em cidades de fronteira: Uruguaiana e Santana do Livramento (RS). Rio de Janeiro, 2006. Dissertação (Mestrado em Geografia) - Universidade Federal do Rio de Janeiro, UFRJ.

BEAUJEU-GARNIER J.; CHABOT, G. Tratado de Geografía Urbana. Buenos Aires: Vicens-Vives, 1970. 587p. (n.711).

BRASIL. Ministério da Integração Nacional. Proposta de reestruturação do Programa de Desenvolvimento da Faixa de Fronteira. Secretaria de Programas Regionais, Programa de Desenvolvimento da Faixa de Fronteira. Brasília, 2005. 
CATAIA, M. A relevância das fronteiras no período atual: unificação técnica e compartimentação política dos territórios. Scripta Nova, v. 11, n. 245, s.p., 2007. Disponível em: http://www.ub.edu/geocrit/sn/sn24521.htm. Acesso em 12 abr. 2019.

CHELOTTI, M.C. Produção desigual do espaço e dinâmica regional da agropecuária na Campanha Gaúcha (Brasil). Observatorium, v.2, n.6, p. 36-67, 2011.

CNA - Censo Nacional Agropecuario. Dirección Provincial de estadísticas y Censos. Buenos Aires, 2008.

COELHO, K.N. de B. Influências urbanas nas cidades fronteira: o caso de Uruguaiana (BR) e Paso de los Libres (AR). Porto Alegre, 2008. Dissertação (Mestrado em Planejamento Urbano e Regional) - Universidade Federal do Rio Grande do Sul, UFRGS.

COLVERO, R.B. Negócios na madrugada: o comércio ilícito e a expansão da economia no extremo oeste (1850-1870). Passo Fundo, 2003. Dissertação (Mestrado em Patrimônio Cultural) - Universidade de Passo Fundo, UPF.

DIETZ, C.I. Cenários contemporâneos da Fronteira Brasil - Argentina: as infra- estruturas estratégicas e o papel dos atores no processo de cooperação/integração transfronteiriça. Porto Alegre, 2008. Dissertação (Mestrado em Geografia) - Universidade Federal do Rio Grande do Sul, UFRGS.

DORNELES, L.L. Guerra Farroupilha: considerações acerca das tensões internas, reivindicações e ganhos reais do decênio revoltoso. Revista Brasileira de História \& Ciências Sociais, v.2, n.4, p. 173-174, 2010.

FARINATTI, L.A.E. Um campo de possibilidades: notas sobre as formas de mão-de-obra na pecuária (Rio Grande do Sul século XIX). História Unisinos, v. 7, n. 8, p. 253-276, ago./dez., 2003.

FERRARI, M. As noções de fronteira em Geografia. Perspectiva Geográfica, v.9, n.10, p. 45-54, 2014.

FLÔRES, J.R.A. A vila de São Borja (1834-1887) numa conjuntura de transição: história sócio-econômica e geopolítica. Canoas, 1996. Dissertação (Mestrado em História) - Universidade do Vale do Rio dos Sinos, UNISINOS.

FONSECA, P.C.D. RS: Economia e Conflitos Políticos na República Velha. Porto Alegre: Mercado Aberto, 1983.

GONÇALVEZ, J.S. Agricultura sob a égide do capital financeiro: passo rumo ao aprofundamento do desenvolvimento dos agronegócios. Informações Econômicas, v.35, n.4, p. 7-36, 2005.

GRIMSON, A. La nación e sus límites. Contrabandistas y exilados en la frontera Argentina-Brasil. Barcelona: Gedisa, 2003.

HERRLEIN, R.J. A transição capitalista no Rio Grande do Sul, 1889-1930: uma nova interpretação. Economia e Sociedade, v. 13, n. 1, p. 175-207, jan./jun. 2004.

IBGE - Instituto Brasileiro de Geografia e Estatística. Censo Agrícola. 1980, 1996, 2006, 2017. Disponível em: https://cidades.ibge.gov.br/brasil/rs/uruguaiana/pesquisa/. Acesso em 17 ago. 2019.

INDEC. 2002. Censo Nacional Agropecuário. Disponível em: www.indec.mecon.ar. Acesso em: 15 abr. 2018.

IRGA - Instituto Rio Grandense do Arroz. Disponível em: https:/ /irga.rs.gov.br/ Acesso em: 12 abr. 2018.

ISABELLE, A. Viagem ao Rio do Prata e ao Rio Grande do Sul. Rio de Janeiro: Zélio Valverde, 1949.

LIMA, R.C. Pequena História Territorial do Brasil: sesmarias e terras devolutas. São Paulo: Secretaria de Estado da Cultura, 1990.

MacARREIN, O.F. et al. La evolución ganadera de la provincia de Corrientes. Universidad Nacional del Nordeste. Corrientes, 2006. (Comunicaciones Científicas y Tecnológicas).

MACHADO, L.O. Limites, Fronteiras, Redes. In: STROHAECKER, T. et al. (Org.). Fronteiras e Espaço Global. Porto Alegre: AGB-Seção Porto Alegre, 1998.

. Estado, territorialidade, redes: cidades gêmeas na zona de fronteira sul-americana. In: SILVEIRA, M.L. (Org.). Continente em chamas: globalização e territórios na América Latina. Rio de janeiro: Civilização Brasileira, 2005. 
MAESTRI, M. O escravo gaúcho: resistência e trabalho. Porto Alegre: Mercado Aberto, 1989.

OPERÉ, F. La Argentina de Rosas. Madri: Biblioteca Virtual de Cervantes, 2011.

OTAZÚ, M.I. Propuesta de Reordenamiento Urbano de Paso de los Libres. Acuerdo UNNE-Municipalidad de Paso de los Libres. Corrientes, 2003.

PESAVENTO, S.J. República Velha Gaúcha: charqueadas, frigoríficos, criadores. Porto Alegre: Movimento/ IEL, 1980.

PONT, R. Campos realengos: formação da fronteira sudoeste do Rio Grande do Sul. Porto Alegre: Renascença, 1983.

QUEIROZ, M.I.P. Pecuária e vida pastoril: sua evolução em duas regiões brasileiras. Revista do Instituto de Estudos Brasileiros, n.19, p. 55-78, 1977.

RANGEL, I. A história da dualidade brasileira. Revista de Economia Política, v.1, n.4, p. 5-34, jan./mar. 1981.

RASCOVAN, A. La integración Regional en espacios globalizados de frontera: Paso de los Libres/ Uruguaiana. In: CONGRESO LATINOAMERICANO DE CIENCIA POLITICA. 5. 2010. Buenos Aires. Anais....

SANTOS, M. Sociedade e espaço: a formação social como teoria e como método. Boletim Paulista de Geografia, n.54, p. 81-99, jun,1977

SCHAFFER, N. Pesquisa do Rio Grande do Sul. Morador e moradia em periferia e cidade de fronteira: Condições socio-económicas em vilas de Santa Ana do Livramento. In: SEMINÁRIO INTEGRACLÓN LATÍNOAMERICANA Y TERRITÓRIO, 1. 1991. Bueno Aires. Anais...

SCHALLER, E.C. El proceso de distribución de la tierra en la provincia de Corrientes (1588-1895). Anuario del CEH, v.1, n. 11, p. 129-180, 2001.

SOARES, F.C. Santa Thereza: um estudo sobre as charqueadas da fronteira Brasil - Uruguai. Santa Maria, 2006. Dissertação (Mestrado em Integração Latino-americana) - Universidade Federal de Santa Maria, UFSM.

ZARTH, P. Do arcaico ao moderno: o Rio Grande do Sul agrário do século XIX. Ijuí: Ed. UNIJUÍ, 2002.

Data de submissão: 27/ jul./2017

Data de aceite: $24 /$ jul./2019 